\title{
CORRECTION
}

\section{Correction to: Network-Level Heterogeneous Traffic Flow Modelling in VISSIM}

\author{
Ranju Mohan ${ }^{1}$ (1) $\cdot$ Susan Eldhose ${ }^{2} \cdot$ Gautham Manoharan ${ }^{1}$
}

Published online: 9 March 2021

(c) Springer Nature Switzerland AG 2021

\section{Correction to: \\ Transportation in Developing Economies (2021) 7:8 \\ https://doi.org/10.1007/s40890-021-00117-4}

In the original publication of the article, the affiliations of the first two authors were published with an error.

The correct affiliations are given in this correction.

${ }^{1}$ Centre for Infrastructure, Sustainable Transportation, and Urban Planning, Indian Institute of Science Bangalore, Bangalore 560012, India

${ }^{2}$ National Institute of Technology, Surathkal, Karnataka 575025, India

The original article has been updated.

The original article can be found online at https://doi.org/10.1007/ s40890-021-00117-4.

Ranju Mohan

ranju@iitj.ac.in

Susan Eldhose

sresusan@gmail.com

Gautham Manoharan

gauthamm@iisc.ac.in

1 Centre for Infrastructure, Sustainable Transportation, and Urban Planning, Indian Institute of Science Bangalore, Bangalore 560012, India

2 National Institute of Technology, Surathkal,

Karnataka 575025, India

Publisher's Note Springer Nature remains neutral with regard to jurisdictional claims in published maps and institutional affiliations. 